\title{
Ligue os pontos. "Livros para colorir", erradicar seu uso nas escolas: um projeto de A/r/tografia Visual
}

Clara Deguines Guillem é licenciada em Belas Artes pela Universidad Complutense de Madrid (UCM) e mestre em Artes Visuais e Educação pela Universidad de Granada (UGR). Realiza dois estágios de pesquisa, um na Universidad de París V Descartes (2017), e outro na Universidad Nacional Autónoma de Honduras (UNAH) (2016). Ilutradora, em 2016 publicou os cinco livros do projeto "Olma y Ofe" em edição digital (www.olmayofe. com). Em 2017, publicou o livro ilutrado “Curucusí". "Bicho de luz" junto a Ana López Seoane, com a qual também publicou recentemente (2019) o livro "Onde residem os contos". Exposições: Exposição individual "Projeto Olma y Ofe" no espaço The Organic co. em Guadalajara (España) em 2017. Entre 2018 e 2019 participou de várias exposições junto ao Coletivo de Mulheres Artistas Guadalajara (CMAG).>claradegem@gmail.com> ORCID: 0000-0001-8821-4588
Resumo 0 texto em questão traz uma reflexão acerca dos livros de ilustração para colorir e seu papel na educação, considerando que eram até pouco tempo voltados ao público infantil. O questionamento que se apresenta é em relação à formação em artes que esta modalidade de livro pode trazer. Considerando a composição gráfica deste tipo de material, observou-se que os mesmos são desprovidos de valores estéticos mais elaborados, são grosseiros e não trazem aprendizado, mas sim atividades repetitivas. A intenção ao apresentar uma nova proposta para este tipo de livro por meio do projeto $\mathrm{A} / \mathrm{r} /$ tografia Visual, é formular materiais que de fato possam contribuir com educação de crianças em pré-escolas.

Palavras chave Arte, Educação, Livro para colorir. 
Ricardo Marin Viadel é licenciado em Belas Artes, Universidad de Barcelona e Doutor em Filosofia e Ciências da Educação, Universidad de Valencia. Foi professor das Universidades de Valencia (1980-81), Barcelona (1981-84) e Complutense de Madrid (1984-88). Atualmente é catedrático de Educação Artística na Faculdade de Bellas Artes da Universidad de Granada e coordenador do programa interuniversitário de doutorado 'Artes e Educação' (http://doctorados.ugr.es/arteducacion/). <ricardom@ugr.es > ORCID: 0000-0001-9918-0627

\section{Connect the dots. Coloring books eradicating their use in schools: a Visual A/r/tography Project}

Abstract The text in question brings a reflection about the illustration books for coloring and their role in education, considering that until recently they were aimed at children. The question that arises is in relation to the training in arts that this type of book can bring. Considering the graphic composition of this type of material, it was observed that they lack more elaborate aesthetic values, are coarse and do not bring learning, but repetitive activities. The intention when presenting a new proposal for this type of book through the Visual A/r/toography project, is to formulate materials that can actually contribute to the education of children in preschools.

Keywords Art, Education, Coloring book.

Sigue la linea. Cuadernos de 'Pinta y Colorea' para acabar con ellos en la escuela: un proyecto de $A / r /$ tografia Visual

Resumen El texto en cuestión trae una reflexión sobre los libros de ilustración para colorear y su papel en la educación, teniendo en cuenta que hasta hace poco estaban destinados a los niños. La pregunta que surge es en relación con la capacitación en artes que puede traer este tipo de libro. Teniendo en cuenta la composición gráfica de este tipo de material, se observó que carecen de valores estéticos más elaborados, son toscos y no aportan aprendizaje, sino actividades repetitivas. La intención al presentar una nueva propuesta para este tipo de libro a través del proyecto Visual $\mathrm{A} / \mathrm{r} /$ toography, es formular materiales que realmente puedan contribuir a la educación de los niños en preescolares.

Palabras clave Arte, Educación, Libro para colorear. 
Fig 1. Sigue la linea. Album ilustrado digital composto por 14 vinhetas Fonte: Clara Deguines Guillem (2015)
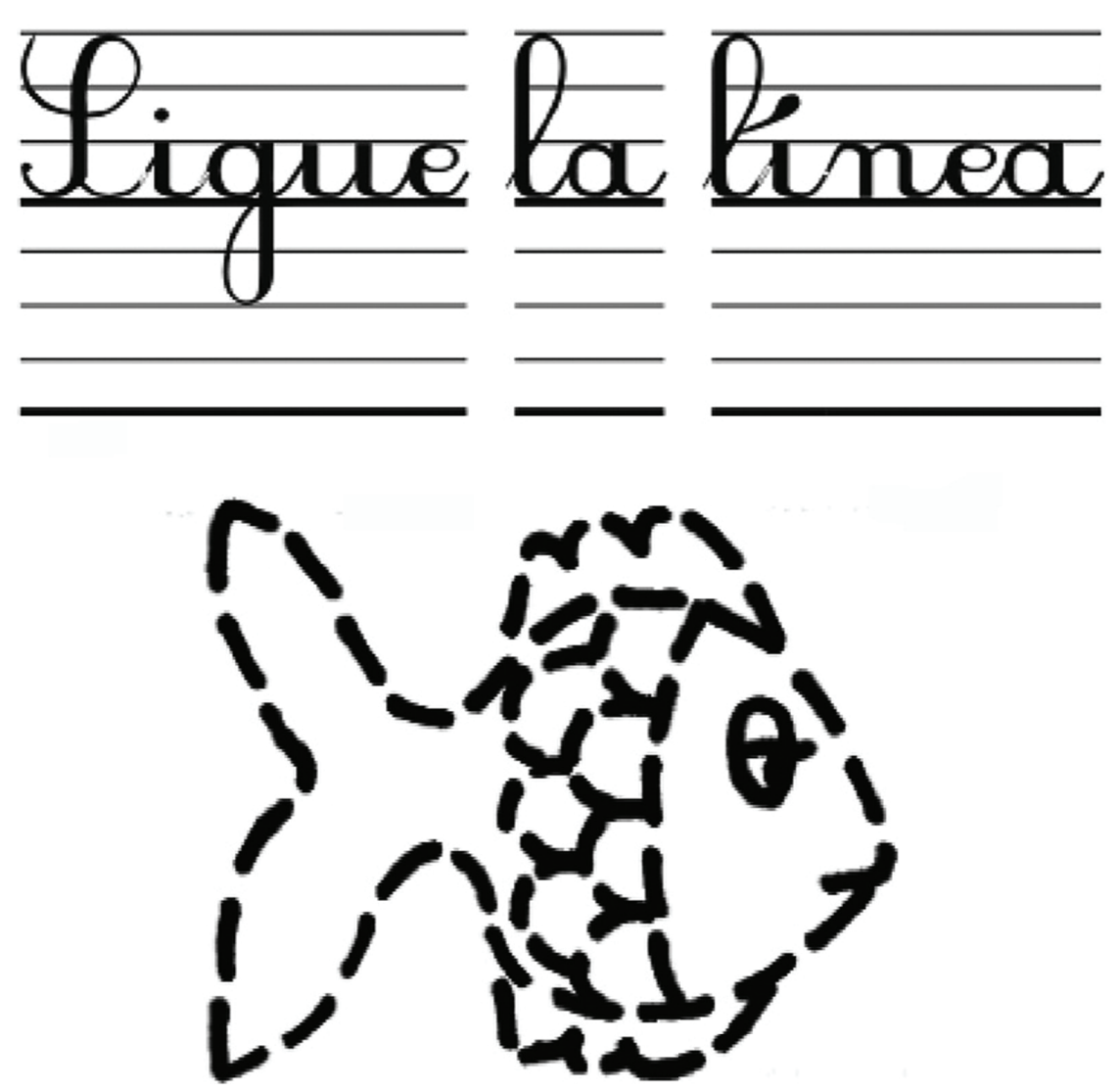

Livros de colorir para meninas e meninos são um produto industrial muito popular que, até recentemente, foram direcionados quase exclusivamente ao público infantil (Walt Disney Company, 2015). Nos últimos anos, os livros de colorir para adultos se tornaram um dos maiores sucessos comerciais da indústria editorial (vários autores, 2014).

Colorir um design impresso é uma atividade divertida e isso é uma das principais razões para a abundância e persistência desse tipo de publicação: eles vem em desenhos de flores, animais, navios, cenas de histórias sagradas ou do circo, e alguns desenhos são de pinturas ou desenhos de artistas.

Livros para colorir publicados, especialmente para o público mais jovem, incluem mais atividades além da coloração, atividades como conectar os pontos para desenhar uma linha ou imagem, ou usando adesivos para completar uma cena.

No contexto educacional, e mais especificamente em relação ao contexto da Educação Artística, colorir os livros levanta algumas questões: O que se aprende na coloração de um design impresso? É uma atividade criativa? Por que esses desenhos têm uma qualidade artística tão sombria? A que eles devem sua popularidade na escola? 
Nossa perspectiva é que os livros de colorir são, na esmagadora maioria, terrivelmente feios, desanimadoramente grossos e muito raramente criativos. A menos que estejamos preparados para considerar que nos divertir com palavras cruzadas é uma atividade interessante para a aprendizagem literária criativa, os livros para colorir não podem ser creditados por contribuir de alguma maneira para o aprendizado da cor, nem o aprendizado das artes visuais.

Devido à proximidade entre as tarefas que esse tipo de livro introduz e as atividades artísticas inerentes à arte, é fácil confundir os dois tipos de atividades. Livros de desenhos para colorir representam elementos e objetos que são normalmente considerados bonito, como pássaros, borboletas, princesas e navios do mar. Quando nós os preenchemos com cores, é inevitável que seu apelo visual é aumentado.

O principal objetivo deste projeto de pesquisa é criar um conjunto de livros de colorir que tragam para iluminar a falácia das propostas artísticas deste tipo de livro: a cor deve ser mantida perfeitamente dentro das linhas de contorno, as linhas que desenhamos não devem se desviar da linha indicada pela sequência de pontos, etc. esses livros demonstram visualmente como eles podem ser transformados criativamente. $O$ conjunto do projeto pode ser compartilhado na página da web: http://www.olmayofe.com/.

A metodologia de pesquisa que utilizamos é baseada em Arte Pesquisa (CAHNMANN-TAYLOR e SIEGESMUND, 2008) e, mais especificamente o projeto educacional, Visual A / $r$ / tography (MARIN-VIADEL \& ROLDAN, 2012) porque eles unem: (a) uma dimensão artística, a criação de um conjunto de livros ilustrados; (b) uma dimensão educaçional, esses livros ilustrados são uma material didático inovador; e (c) uma dimensão de pesquisa, para verificar a eficácia desses materiais na transformação criativa de Educação artística em creches e escolas primárias (LUNA RODRÍGUEZ, 2014).

O principal desafio na criação desses livros de ilustrações é alavancar algumas das qualidades inerentes aos livros para colorir, como sua simplicidade, reconhecimento fácil e imediato de seus elementos representantes e sua ausência de texto escrito.

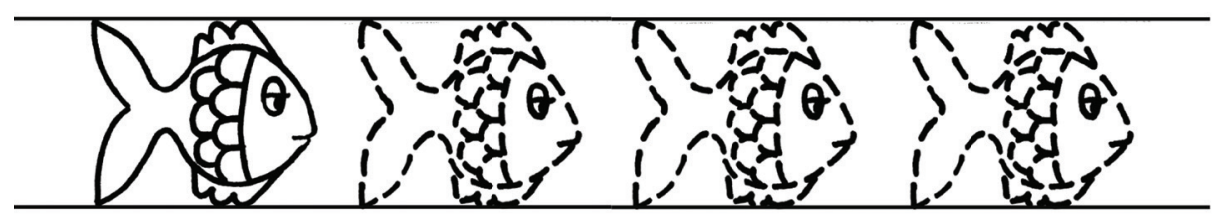



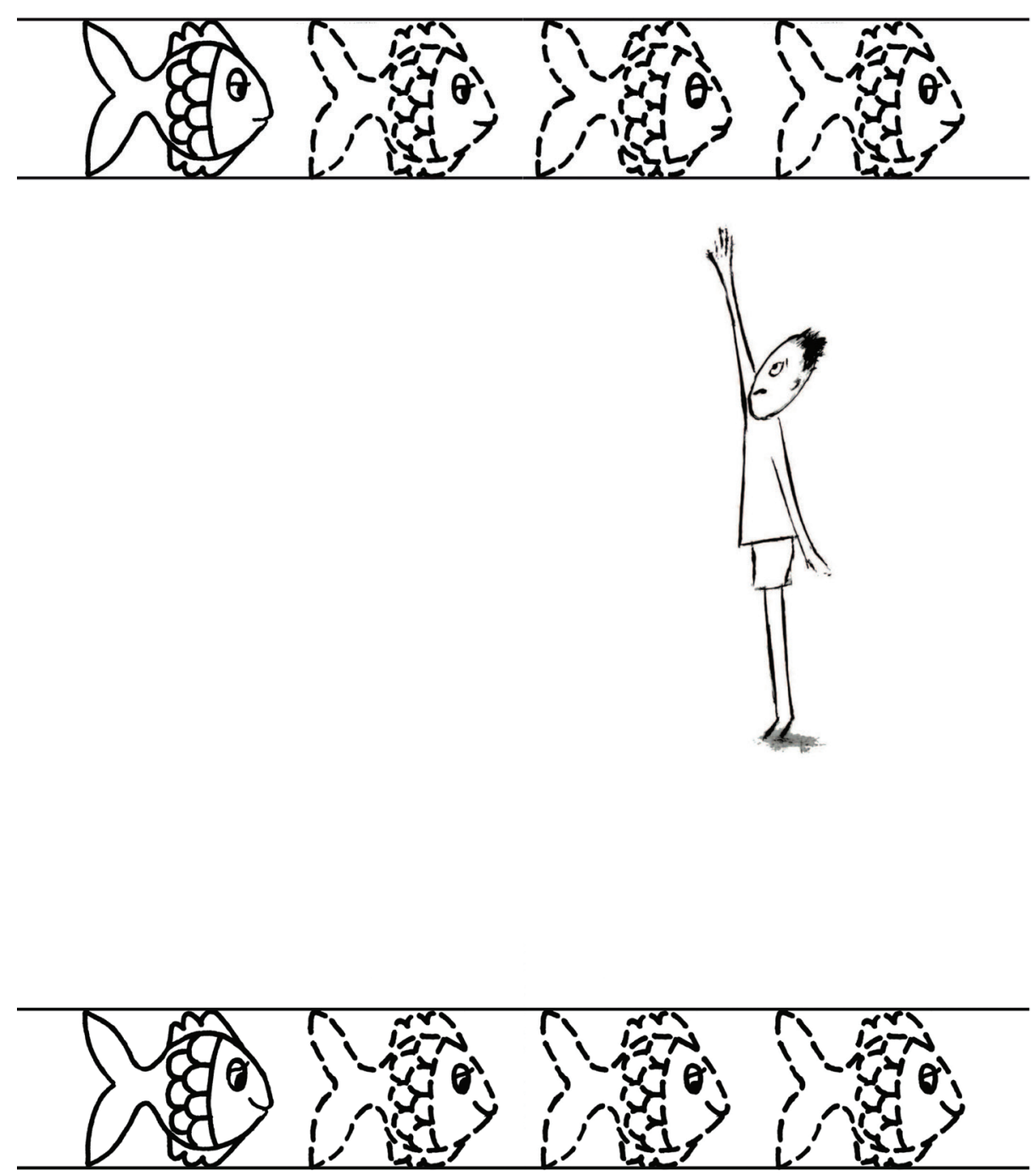

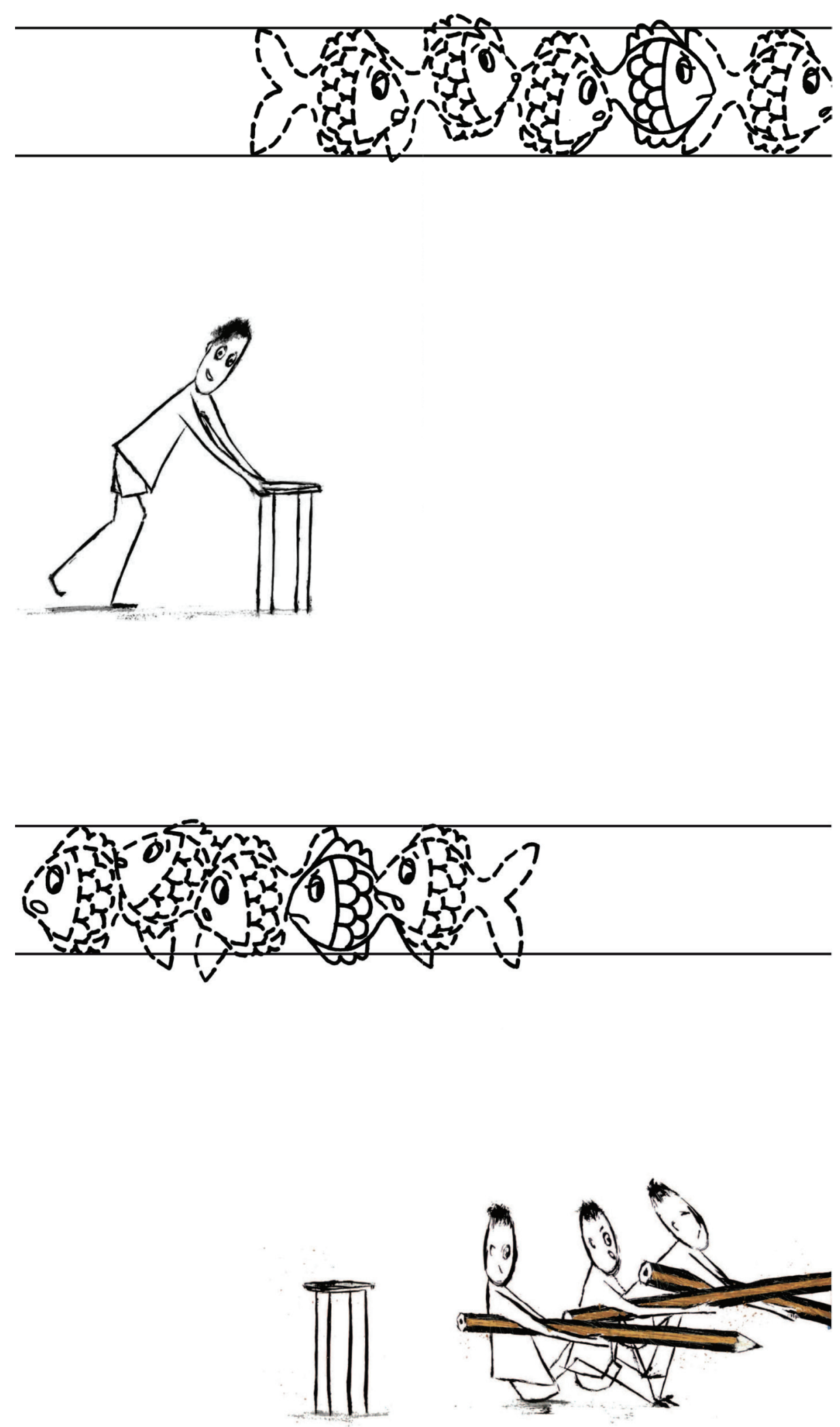

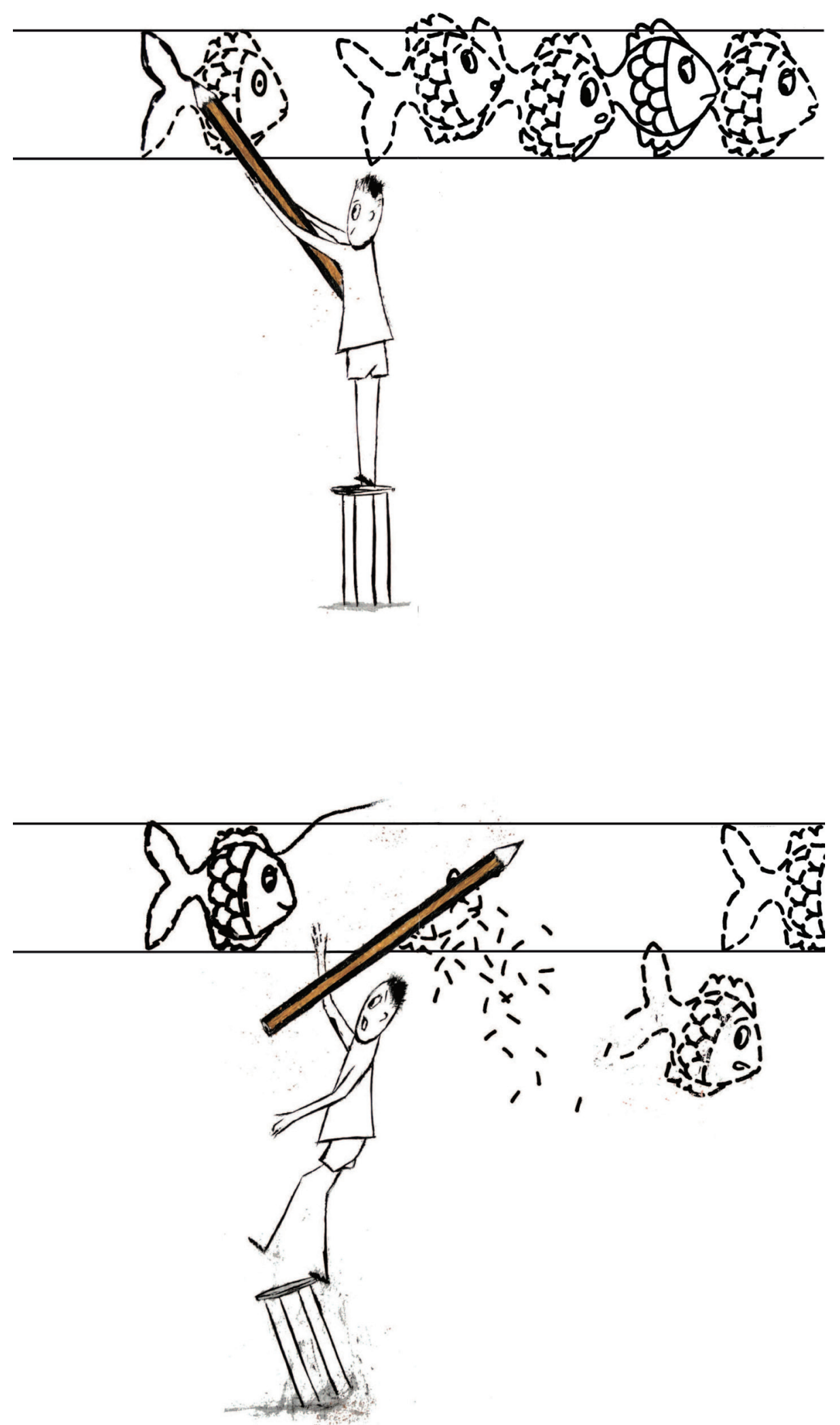

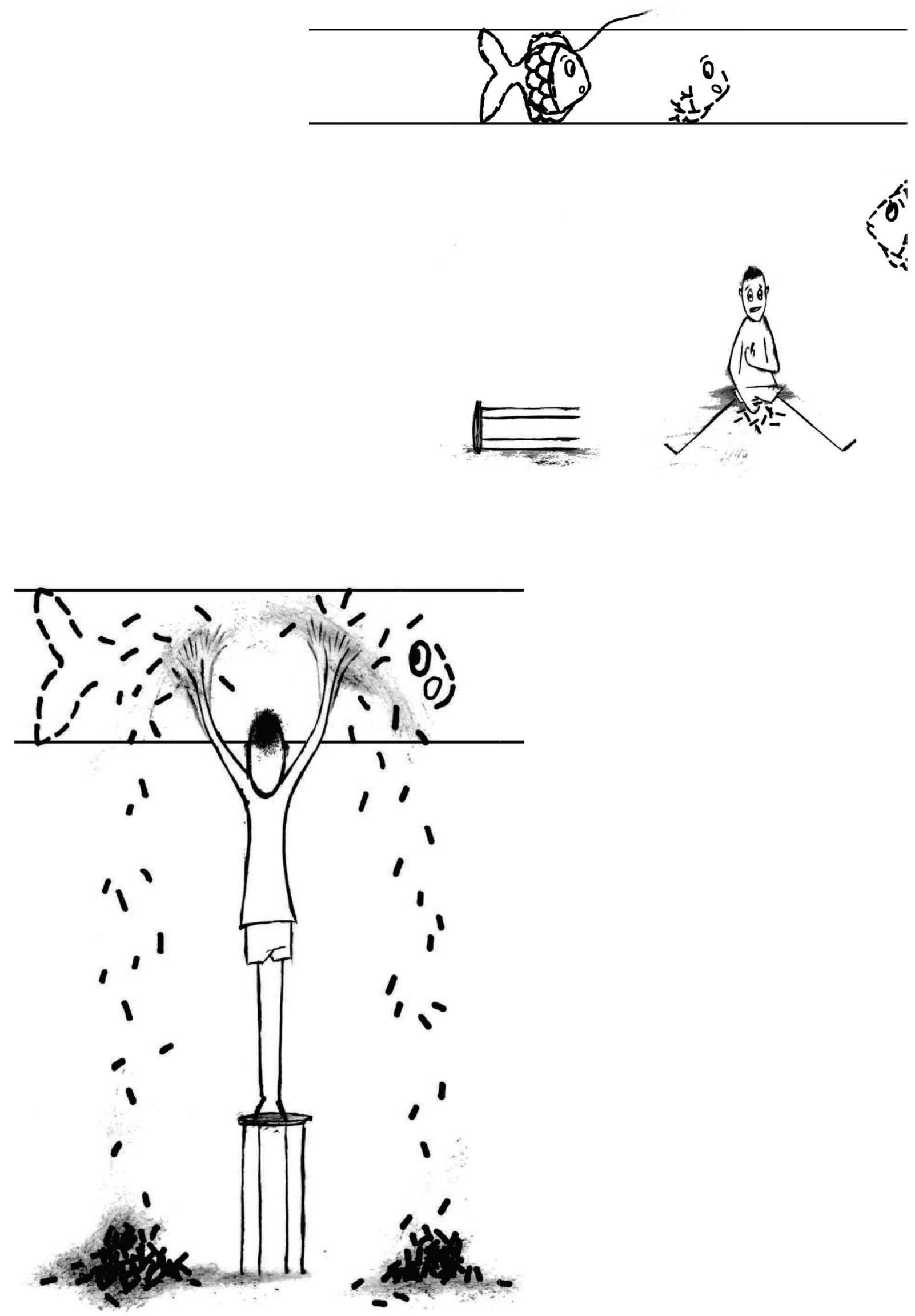

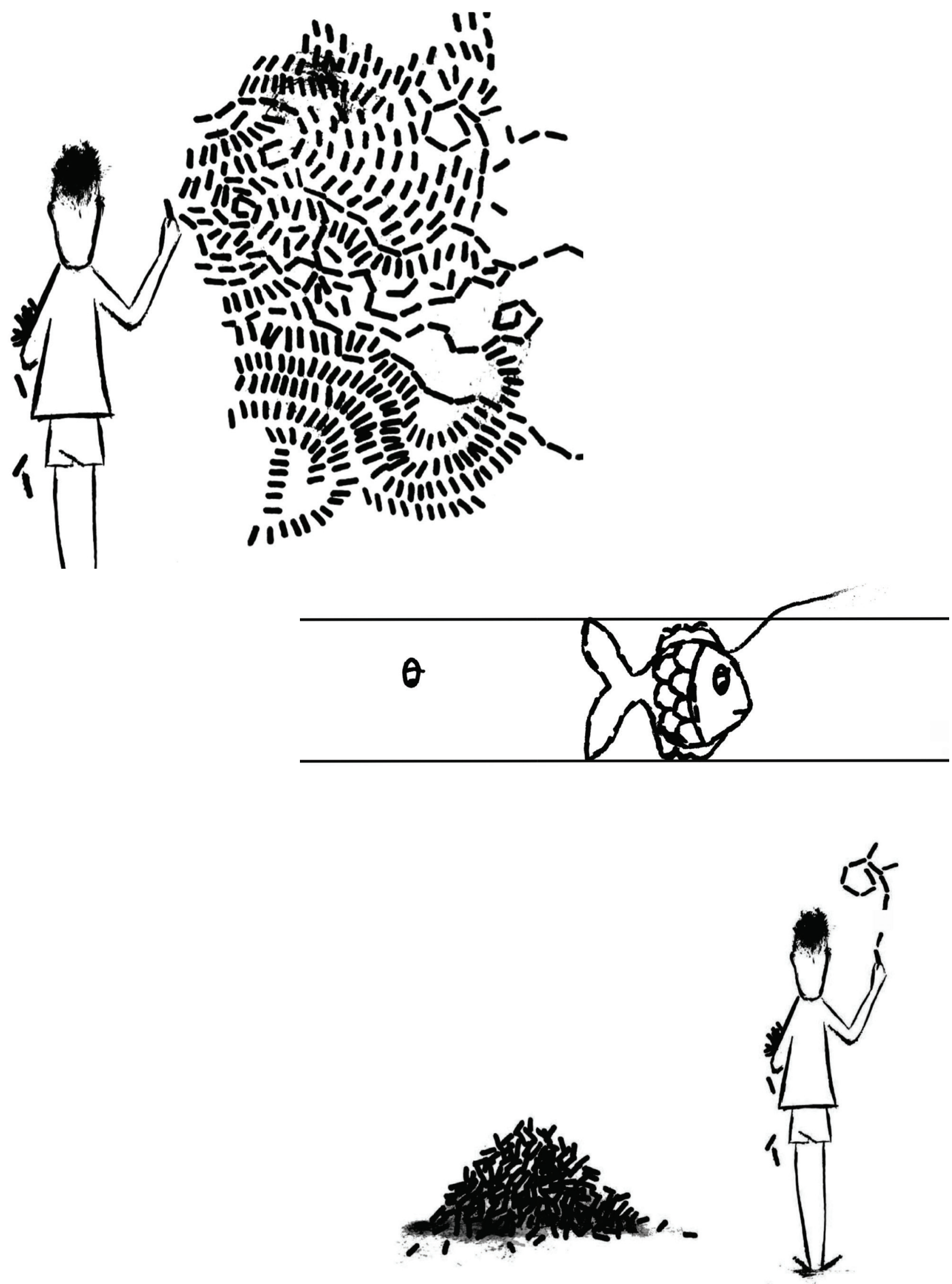

DATJournal v. 5 n.2 2020 


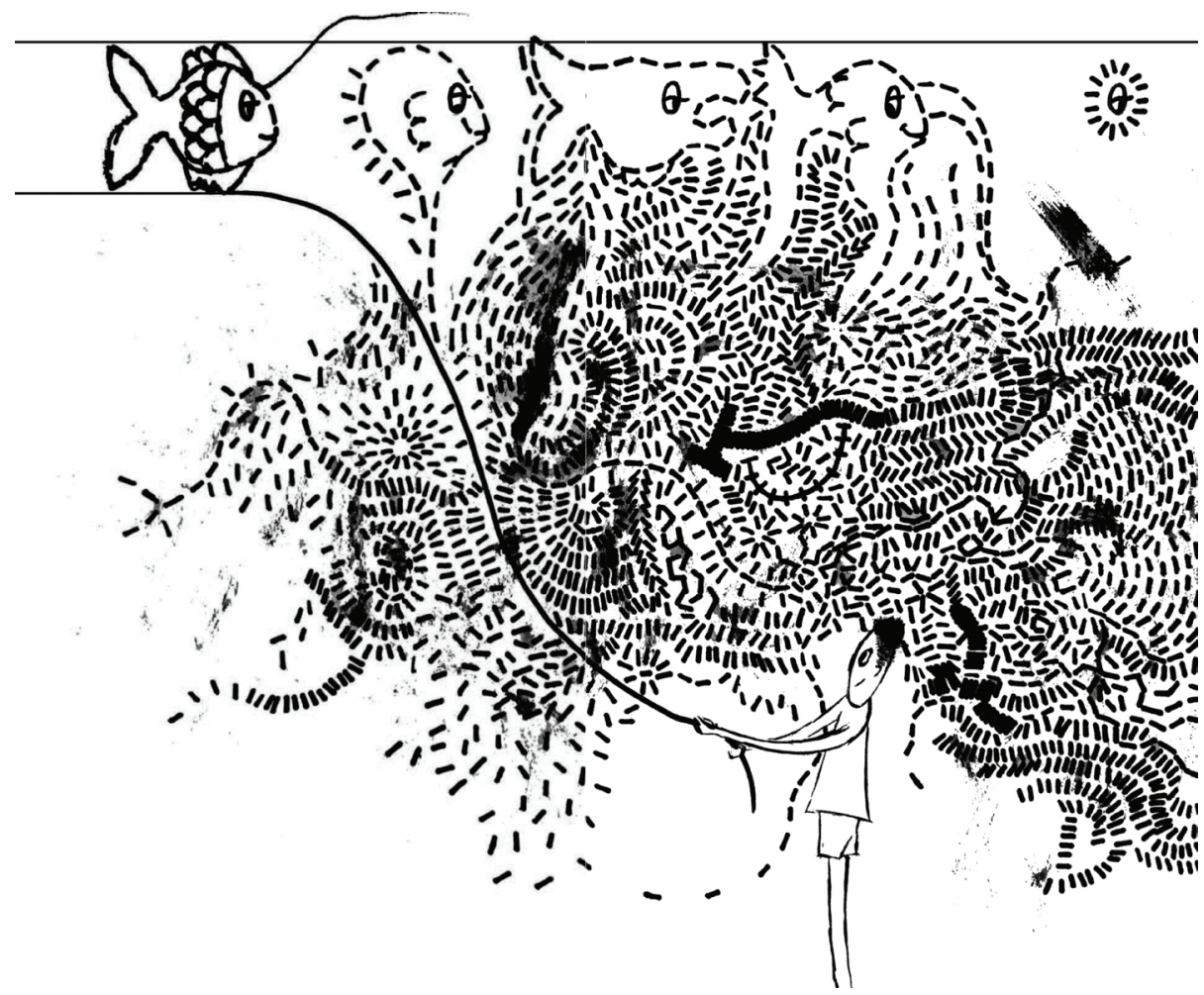

Cada um dos livros ilustrados criados para esta pesquisa, este texto mostra o resumo de um deles, cria uma história gráfica que demonstra a crueza e a falta de criatividade dos livros para colorir.

Como os livros para colorir podem ser projetados para demonstrar a falácia educacional desse tipo de livro? A estratégia autorreferencial tem sido amplamente utilizada nas artes visuais, como nas pinturas e desenhos de René Magritte (1929) em que um cano não é um cachimbo, ou na peça de Luigi Pirandello (2001) em que os personagens procuram um autor, e em filme (COEN e COEN, 2016). Aqui interessa destacarmos o uso crítico da auto-referencialidade, colocando o meio em questão tanto quanto seu uso típico na cultura visual contemporânea. Este é o presente nas fotomontagens de Josep Renau (1977) em que as estratégias visuais típicas de publicidade comercial foram utilizadas para denunciar as contradições no 'American Way of Life'; e mais recentemente os pôsteres, outdoors e instalações por Barbara Kruger (1998) sobre sexismo e violência baseada em gênero ou a "sub-publicidade" de Banksy (http://banksy.co.uk/).

Os novos livros para colorir criados neste Projeto de A/r/tografia Visual não são livros para colorir, mas livros que demonstram a futilidade educacional de livros para colorir. 


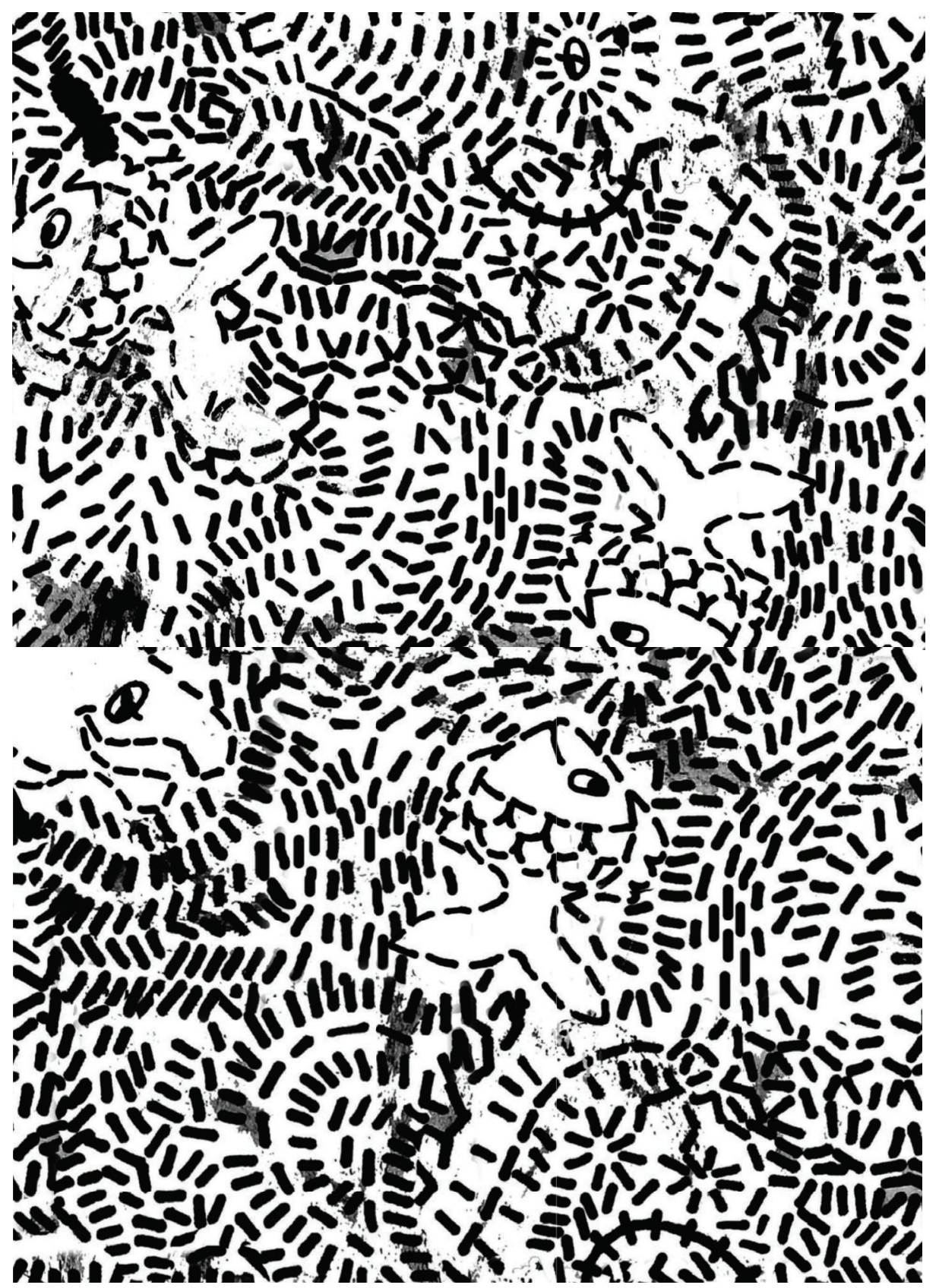




\section{Referências}

Autores Vários. Arte Antiestres. 100 jardines para colorear In: Anti-stress art. 100 gardens coloring pages. Barcelona: Plaza \& Janes, 2014.

CAHNMANN-TAYLOR, M.; SIEGESMUND, R. (eds.). Arts-Based Research In Education. Foundations for Practice. In: Investigacion Basada en Artes en Educacion. Fundamentacion de la practica. New York: Routledge, 2008.

COEN, J.; COEN, E.; BEVAN, T.; FELLNER, E. (producers) \& Coen, J.; Coen, E. (directors). Hail! Caesar In: !Ave! Cesar. United States: Universal Pictures, 2016

KRUGER, B. Mando a distancia: poder, culturas y el mundo de las apariencias In: Remote Control: Power, Cultures, and the World of Appearances. Madrid: Tecnos, 1998.

LUNA Rodriguez, C. Cuento ilustrado realizado con y para personas con discapacidad intelectual: propuesta de un lenguaje grafico para la buena comprension de historias por parte de personas que no tengan adquirida la lectoescritura. In: Illustrated book made with and for people with intellectual disabilities: proposal for a graphical language for a proper understanding of stories by people who do not have acquired literacy. Granada: Universidad de Granada, 2014. Disponível em: http://0-hera.ugr.es.adrastea. ugr.es/tesisugr/24182540.pdf.

MAGRITTE, R.. La trahison des images. Ceci n'est pas une pipe. In: La traicion de las imagenes. Esto no es una pipa. | The Treachery of Images. This is Not a Pipe. Oleo sobre tela, 60.33 x 81.12 x 2.54 cm. Los Angeles County Museum of Art: Los Angeles, 1929. Disponível em: http://collections.lacma.org/node/239578.

MARIN-VIADEL, R. \& ROLDAN, J. Quality Criteria in Visual A/r/tography Photo Essays: European Perspectives After Daumier's Graphic Ideas. In: Criterios de calidad en Fotoensayos de A/r/tografia Visual: Una perspectiva europea a partir de las ideas graficas de Daumier. Visual Arts Research, 38 (2), 13-25, 2012.

PIRANDELLO, L. Seis personajes en busca de autor: comedia por hacer. In: Six Characters In Search of an Author. Madrid: Edaf, 2001 [1921].

RENAU, J. The American Way of Life. Fotomontajes: 1952-1966. Barcelona: Gustavo. 1977. WALT Disney Company. Princesas. Pinta mi mundo. In: Princesses. Paint My World. Barcelona: Libros Disney, 2015 